\section{Educational Psychological Counselling and Collective Competence Improvement Related to Autism/Autism Spectrum Disorders (ASD)}

\author{
Kamil Özerk $^{\mathrm{a},{ }^{*}}$, Elise Öksendal ${ }^{\mathrm{b}}$, Meral Özerk ${ }^{\mathrm{b}}$
}

\author{
Received: 15 September 2017 \\ Revised: 29 October 2017 \\ Accepted: 22 November 2017 \\ ISSN: 1307-9298 \\ Copyright (C) IEJEE \\ www.iejee.com
}

DOI: 10.26822/iejee.2018336192

\begin{abstract}
A collective Competence Improvement Project (CIP) was conducted for educational psychological counselors $(n=5)$ along with teachers $(n=11)$, special education teachers $(n=7)$, and child and youth workers $(n=11)$. All of the participants were involved in the training and teaching of children with autism/ASD in a small municipality in Norway. The CIP focused primarily on competence improvement in the participants' overall knowledge and theoretical conceptions about autism/ASD. Additionally, other goals included competence improvement in Discrete Trial Teaching (DTT), Pivotal Response Training (PRT), and Social Stories ${ }^{T M}$ (SS). The results demonstrate that the CIP contributed to improvements in some of these targeted areas but not in all. Educational psychological counsellors and special education teachers benefited more and satisfactorily from the CIP than teachers and child and youth workers (CYWs). It is now clear that achieving significant improvement in competency does not necessarily equate to satisfactory improvement. Additionally, improving the professionals' theoretical knowledge is important, but it does not necessary lead to improving their operational knowledge--their capacity for implementing their knowledge in practice. This paper presents the background, implementation, and results of the CIP, and it closes with a discussion of the findings and conclusions about their implications for future CIPs and research.
\end{abstract}

Keywords: Educational psychological counselling, autism/ASD, collective competence improvement.

\section{Introduction}

This paper assesses a competence improvement project (CIP) for educational psychological counselors along with three other professional groups: a) teachers, b) special education teachers, and c) child and youth workers (CYWs). All were involved in training and teaching children with ASD in one of Norway's municipalities. The population of the municipality was about 24,000 when the CIP began in 2014. The initiative was welcomed by the municipality's school administration and the leadership of Educational Psychological Counseling Services in the municipality. The CIP was conducted by STATPED, a national agency for special education support systems, starting in 2014 and finishing in 2016. The contents of the CIP included scheduled courses based on a syllabus focused on the book Autism and Pedagogy as well as articles, case discussions, reflections on participants' own practices, and demonstrations of tactics, strategies, procedures, and methods related to training and teaching children with autism/ASD. STATPED chose to collaborate with one of the researchers at the University of Oslo for monitoring the CIP. The data used in this paper was collected after pre-test and post-test procedures, then coded and analyzed in close collaboration with the second author. The third author acted as the main instructor for the CIP but did not know the content of the survey until after the CIP was completed.
A short description of the Educational Psychological Counseling Services in the Norwegian System and The Rights of Children With Special Needs

In Norway, educational administration has three levels. The state level is responsible for higher education institutions such as Universities and Colleges.

Next, the county level focuses on the country's 19 counties, wherein upper secondary education for children between the ages of 16 and 19 is the responsibility of school administration in each county. Upper secondary education and training is a right but not compulsory.

The third level is the municipality level. Across approximately 425 municipalities in Norway, responsibilities include providing ten years of basic school education for children between six and 16 years of age. Basic school education is both a right and compulsory across the country, though pre-schools and kindergartens are not compulsory. Tuition for having a child between 1-5 years of age in these institutions is paid by the parents, but a great portion of the expenses of kindergartens are subsidized by the state.

The founding principle of primary and secondary education in Norway is equity and adapted teaching for all, based on a common National Curriculum. According to The National Curriculum for the Knowledge Promotion and § 1-3

\footnotetext{
${ }^{a, *}$ Corresponding author: Kamil Ozerk, Department of Education, University of Oslo, Sem Saelands vei 7, 0317 Oslo, Norway. Phone:+4722855347, EMail: Kamil.Ozerk@iped.uio.no

${ }^{\mathrm{b}}$ STATPED-Department of Complex Learning Disabilities Pb. 4416 Nydalen, Oslo, Norway. E-mail addresses: (E. Oksendal) Elise.Oksendal@statped.no; (M. Ozerk) Meral.Ozerk@statped.no
} 
of the Education Act of 2009, education in school is to be adapted to the individual pupil's abilities and capabilities:

"Adapted education within the community of pupils is a basic premise of the comprehensive school for all. The education shall be adapted so that the pupils can contribute to the community and also experience the joy of mastering tasks and reaching their goals.

The diversity of pupil backgrounds, aptitudes, interests and talents shall be matched with a diversity of challenges in the education. Regardless of gender, age, social, geographical, cultural or language background, all pupils shall have equally good opportunities to develop through working with their subjects in an inclusive learning environment. Adapted teaching for each and every pupil is characterized by variation in the use of subject materials, ways of working and teaching aids, as well as variation in the structure and intensity of the education." (Ministry of Education and Research: National Curriculum for Knowledge Promotion in Primary and Secondary Education and Training 2006, p. 4-5)

Furthermore The National Curriculum for the Knowledge Promotion states the following related to adapted education:

"The provisions governing special education shall be applied when more comprehensive adaptation is required than what can be arranged within the framework of the regular teaching." (National Curriculum for Knowledge Promotion in Primary and Secondary Education and Training 2006, p. 5)

When it comes to the right to special education, the Norwegian Education Act of 1998 states the following about the right to special education:

"Section 5-1. The right to special education

Pupils who either do not or are unable to benefit satisfactorily from ordinary teaching have the right to special education. In assessing what kind of instruction shall be provided, particular emphasis shall be placed on the pupil's developmental prospects. The content of the courses offered shall be such that the pupil receives adequate benefit from the instruction as a whole in relation to other pupils and in relation to educational objectives that are realistic for the pupil. Pupils who receive special education shall have the same total number of teaching hours as other pupils."

The Norwegian Educational Act of 1998 also contains a section about Educational-Psychological Services:

\section{"§ 5-6. Educational-Psychological Service}

Each municipality and each county must have an educational-psychological services. The educationalpsychological services in one municipality can be organized in cooperation with other municipalities or with the county.

Educational-psychological services will help the school in the field of competence development and organizational development to improve the conditions for training and teaching of students with special needs. The educational psychological services will ensure that an expert assessment is conducted in accordance with the low."

When a child receives the diagnosis of "Autism / Autism Spectrum Disorders" by a specialist in Child and Adolescent Psychiatric Services in collaboration with educational psychological counselling services, the child with autism/ASD has the right to receive 'special education' in accordance with $\S 5-1$. Additional funding of special education (individual, in group, in self- contained community, or in ordinary classroom) is also public. Another section in the Education Act, Section 5-5, states the following:

"For students receiving special education, an individual education plan shall be prepared. The plan will show the goals and content of the training and teaching and how these will be conducted."

The importance of Educational Psychological Counseling and the competence of counselors

As one can see, in the Norwegian system, the Educational Psychological Counseling Services play an important role because they are responsible for educational psychological assessment prior to diagnosis and then for counseling after diagnosis. Referrals, educational psychological assessments, preparing individual education plans (IEPs), and decisions about the child's training and teaching are done after informed consent of the parents. Educational psychological counselors (EPCS) then work in close collaboration with psychiatric services, school administrators, teachers, special education teachers, and parents. Their competence is thus of the utmost importance within the field of special education or special needs education.

In order to become an educational psychological counselor, one must have a specialized Master's degree in educational-psychological counseling which can take 5-6 years of higher education. Even with their degree and extensive educational background, the counselors must also continuously make time for competence improvement in order to stay up to date with new and emerging knowledge relevant to educational and psychological counseling as well as to meet new challenges in the schools in their municipalities or counties. This is also true for the teachers, special education teachers, and child and youth workers. For the improvement of learning conditions of children, the practitioner's learning is crucial (Darling-Hammond and Sykes, 1999; Darling-Hammond, Wie, Andree, Richardson \& Orphanos 2009; Fullan, 1992; Koegel, Kim \& Koegel, 2014). Teachers in the Norwegian education system usually have 3-4 years of education, while special education teachers have 4-5 years of education (teacher education plus further education - at least one year's specialization in special education/education of children with special needs). Child and youth workers earn a diploma after 4 years of education at upper secondary schools: 2 years at school and 2 years of supervised practicum.

The school administration and leadership of Educational Psychological Counseling Services (EPCS) in the CIP- 
municipality learned in 2014 that the training and teaching of children with autism/ASD was one of those fields that needed competence improvement. They contacted STATPED-- a national agency for special education which has expertise about autism/ASD--and asked for the competence improvement project (CIP) for training and teaching of children with autism. The data in this paper is taken from this competence improvement project (CIP).

\section{Autism/Autism spectrum disorders (ASD)}

Autism is a neuro-developmental disability that affects how a person communicates with and relates to other people, as well as how they experience the world around them (NAS, 2016). Autism and its related disorders comprise the autism spectrum disorders (ASD). Children with autism/ASD have varying levels of deficiencies in social behavior, communication, limited interests, and rituals and stereotype behaviors. The course of ASD symptoms appears to be life-long for the majority of the cases. Their problems in social communication, behavior, and social interaction with others and many cases additional disorders make it difficult for many persons with autism/ASD to live independently (Matson and Kozlowski 2011). Autism spectrum disorder (ASD) is thus a complex developmental disability (Autism Society of USA, 2016). Prevalence studies in many countries (Baron-Cohen, Scott, Allison, Williams, Bolton, Matthews \& Brayne, 2009; Cardinal and Griffiths, 2016; Fombonne, Quirke and Hagen, 2011; Özerk, 2016; Zablotsky, Black, Maenner, Schieve \& Blumberg, 2015;) show that during the last decade there has been a considerable rise in the prevalence rate for autism/ASD around the globe.

\section{Children with autism/ASD in the CIP municipality}

As mentioned earlier, the CIP was launched in 2014 and completed in 2016. The triggering reason for CIP within the field of autism/ASD was the rise of the number of children with autism/ASD. During the $80 \mathrm{~s}$ and $90 \mathrm{~s}$, one in 1,000 children received the diagnosis of autism/ASD in Norway (Gundersen \& Hem, 2005) which was similar to the prevalence rates over the same period in the USA (Frea \& Vittimberga, 2000). But for some years before the CIP was launched, two Norwegian studies showed that one in 166 children under 10 years of age (Stoltenberg, Schjølberg, Bresnahan, Hornig, Hirtz, Dayl et. al. 2010) and one in 125 children age 11 were diagnosed with autism/ASD in Norway (Surén, Bakken, Aase, Chin, Gunnes, Lie et al. 2012).

The CIP municipality, with its approximately 24,000 inhabitants, is located in one of the largest counties in Norway. In the following figure we'll illustrate the prevalence of autism/ASD among 1-16 years old children. The data is based on information, numbers, and statistics provided by the CIP-municipality's Educational Psychological Counseling Services, the Norwegian Directorate of Health, the registry of patients, and Norwegian Statistics.

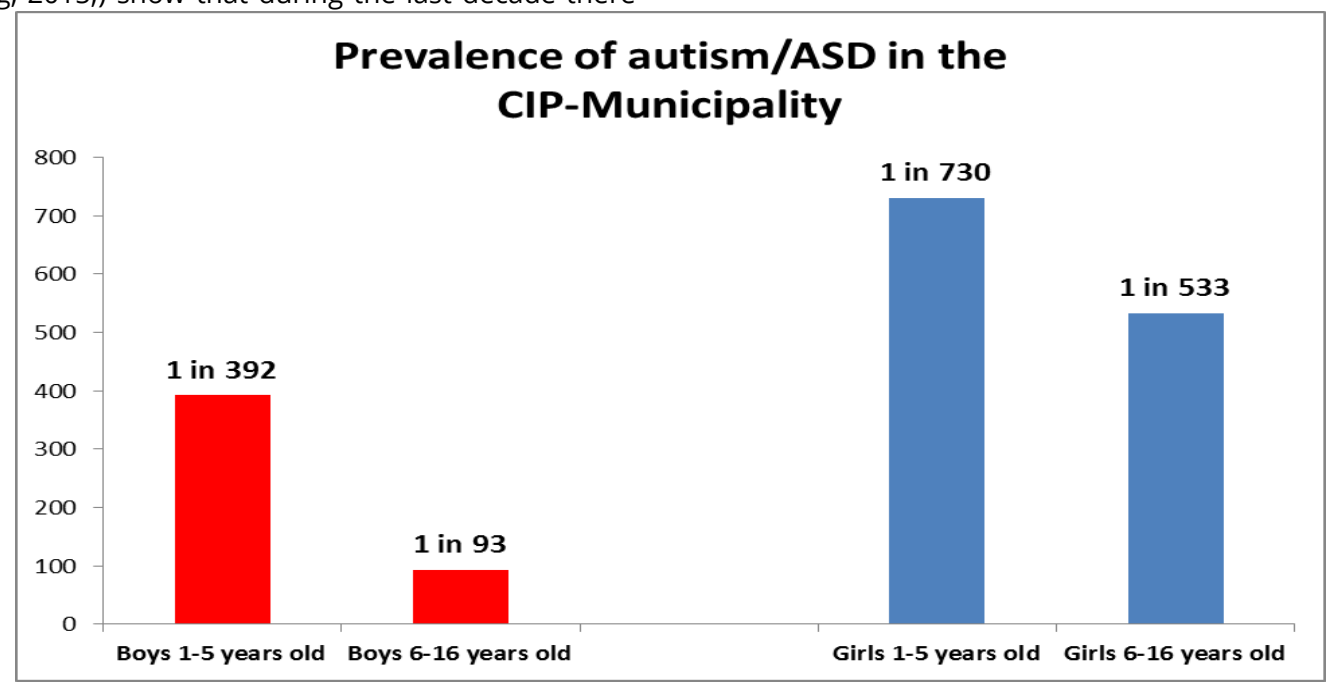

Figure 1. Prevalence of autism /ASD in the CIP-municipality

As can be seen in Figure 1, the prevalence of autism among boys below the school age is 1 in 392 and among the girls 1 in 730. Male-to-female ration for this age group is 1:1.9. On the other hand, 1 in 93 boys and 1 in 533 girls at school age (6-16 years old) have the diagnosis of autism/ASD. Male-to-female ratio for this group is 1:5.7. On the bases of these figures, one can say that there was a 'good' reason for the CIP-municipality's interest in competence improvement within the field of autism/ASD.

\section{The participants in the Competence Improvement Project}

We have chosen to use the word "collective" in the title of our paper. The main reason for this was that even though the first initiative for the CIP came from Educational Psychological Counselling Services and the CIP municipality asking directly for a CIP, the project also included a) teachers, b) special education teachers (Special ed. teachers), and c) child and youth workers. This was proposed by STATPED, and both parties were agreed on it. The sample in our paper is comprised of four different professional groups. There were initially 46 participants in the CIP, but 12 of them (teachers, special ed. teachers, and child and youth workers) have not been included in our study because they were absent too often or they did not participate in enough classes and/or they did not answer all of the questions in the 'post-test'. Therefore, the sample 
in the CIP is comprised of 34 participants who participated with minimum or no absences (minimum $80 \%$ participation) and who received a certificate of attendance upon completion of the CIP. All participants but two were women.

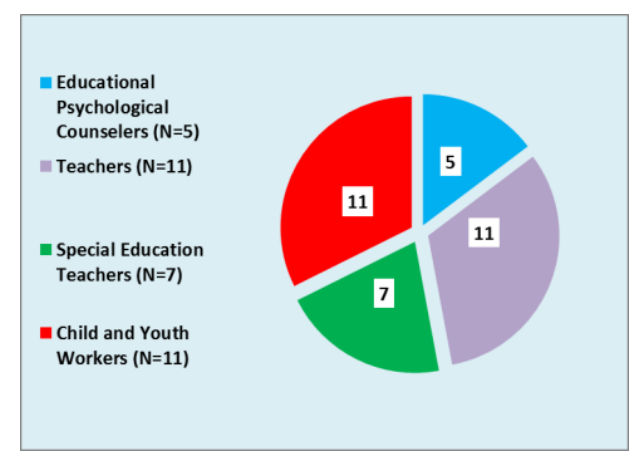

The syllabus of the Competence Improvement Project (CIP)
When the CIP-municipality asked for a CIP from STATPED (A National Service for Special Needs Education), a CIP team was established. This CIP-team was made up of two senior special ed. advisers from STATPED (the second and third authors of this paper), an educational psychological counselor (EPC) from the CIP-municipality, and a researcher from the University of Oslo (the first author of this paper). The EPC coordinated the cooperation between the collaborating partners, and she also provided the CIP with anonymous cases from the kindergartens and schools in the CIP-municipality.

The CIP-team created its syllabus, with the CIP covering topics mainly from the book Autism and Pedagogy (Özerk \& Özerk, 2013) and Social Stories ${ }^{\mathrm{TM}}$ (Fjæron-Gronum, 2007). The following table (1) shows the syllabus of the CIP.

The CIP was implemented through half-day-long, in-person arrangements as afternoon classes. The following table (2) shows the schedules and activities during the CIP-period:

Table 1. The syllabus of the Competence Improvement Project

\begin{tabular}{|c|c|}
\hline \multicolumn{2}{|c|}{ THE CONTENT OF COMPETENCE IMPROVEMENT PROJECT (CIP) } \\
\hline $\begin{array}{l}\text {-What is autism and ASD? } \\
\text {-Historical perspectives on autism and ASD }\end{array}$ & $\begin{array}{l}\text {-Methods, models, tactics, principles technologies for, } \\
\text { training and teaching of children with autism/ASD }\end{array}$ \\
\hline $\begin{array}{l}\text {-The purpose of the CIP and the importance of a collective } \\
\text { competence improvement }\end{array}$ & -Discrete Trial Teaching of children with autism / ASD \\
\hline -Autism \& ASD in DSM 4 \& proposed changes in DSM5 & -Pivotal Response Training for children with autism/ASD \\
\hline $\begin{array}{l}\text {-Prevalence of autism / ASD international } \\
\text {-Prevalence of Autism/ASD in Norway }\end{array}$ & $\begin{array}{l}\text {-'Social Stories }{ }^{\mathrm{TM} M} \text { as a method for training and teaching of } \\
\text { children with autism/ASD }\end{array}$ \\
\hline $\begin{array}{l}\text {-Comorbidity and autism } \\
\text {-Executive functions }\end{array}$ & $\begin{array}{l}\text {-Behavioral theory and autism/ASD } \\
\text {-Cognitive theory and autism/ASD } \\
\text {-Developmental perspective on autism/ASD }\end{array}$ \\
\hline $\begin{array}{l}\text {-Autism/ASD in the light of developmental theory } \\
\text {-Autism / ASD in the light of behavioral theory } \\
\text {-Autism / ASD in the light of cognitive theory }\end{array}$ & $\begin{array}{l}\text {-Educational and psychological counseling within the field of } \\
\text { autism / ASD }\end{array}$ \\
\hline $\begin{array}{l}\text {-Educational assessment of autism/ASF } \\
\text {-Intervention for children with autism/ASD }\end{array}$ & $\begin{array}{l}\text {-Inclusion } \\
\text {-Peer relationship } \\
\text {-Generalization of skills and behaviors }\end{array}$ \\
\hline $\begin{array}{l}\text {-Collaboration between the teachers, special ed. teachers, } \\
\text { child and youth workers, and the parents of children with } \\
\text { autism IASD }\end{array}$ & -Legislations related to special education \\
\hline
\end{tabular}

Table 2. The class schedule and the activities in CIP

\begin{tabular}{|c|c|c|}
\hline Semester & Meetings & $\begin{array}{l}\text { Main activities to cover the content of the CIP's } \\
\text { syllabus }\end{array}$ \\
\hline \multirow{2}{*}{ Fall-2014 } & Two meetings in Oct. 2014 & $\begin{array}{c}\text {-Pre-test } \\
\text {-Lecturing: Topics from the syllabus }\end{array}$ \\
\hline & Two meetings in Nov. 2014 & $\begin{array}{c}\text {-Case presentations and discussions based on video-films } \\
\text {-Legislative and ethical issues }\end{array}$ \\
\hline \multirow{4}{*}{ Spring-2015 } & & -Lecturing: Topics from the syllabus \\
\hline & Two meetings in Feb. 2015 & -Case discussion of anonymous cases \\
\hline & Two meetings in Mars. 201 & -Workshop on intervention/methods \\
\hline & Two meetings in April 2015 & -One of the meetings was only for EPCS \\
\hline \multirow[t]{2}{*}{ Fall-2015 } & Two meetings in Sept. 2015 & $\begin{array}{l}\text {-Lecturing: Topics from the syllabus } \\
\text {-Case discussion of anonymous cases }\end{array}$ \\
\hline & Two meetings in Oct. 2015 & $\begin{array}{l}\text {-Workshop on intervention/methods } \\
\text {-Case presentation and discussion based on video about } \\
\text { children with autism/ASD }\end{array}$ \\
\hline
\end{tabular}




\begin{tabular}{cc}
\hline Spring-2016 meetings in January 2016 & -Lecturing: Topics from the syllabus \\
& -Case discussion \\
& -Summarizing the CIP \\
& -Post-test \\
\hline
\end{tabular}

\section{Methodology}

The data in this paper was gathered through two questionnaires. These questionnaires were developed by two of the authors without sharing any information with the third (because she was the main instructor at the CIP). We followed a standard pre-test - post-test procedure and asked the participants to fill out our questionnaire in the first hour of the first session of the CIP (pre-test). Following completion of the CIP, we administered our second questionnaire (post-test). In the pre-test questionnaire, we asked questions about the participants' knowledge, conceptions, assumptions, and experiences related to autism/ASD and the training and teaching of children with autism/ASD. The post-test also asked questions about the participants' knowledge, conceptions, assumptions, and experiences having to do with autism/ASD and the training and teaching of children with autism/ASD after having participated in the CIP during the previous two years. In the post-test segment, we employed some linguistic adaptations and some changes in the order of the questions. We ensured the anonymity of the participants by not asking for their names and have treated our data without mention of the name of the CIP's municipality or the name of its county. We have coded and analyzed our data with SPSS. Most of the actual figures in our paper were obtained by using EXCEL. This type of research was a part of written collaboration agreements between the CIPmunicipality and STATPED, and between STATPED and the University of Oslo.

\section{Presentation of the results}

One of the central goals of our pre-test questionnaire was to get a clear idea of the EPCs', teachers', special. ed. teachers', and child and youth workers' (CYWs) overall knowledge of autism /ASD in their present work in 2014. They gave answers based on an ordinal scale: 1: To a very little degree, 2: To a little degree, 3: To some degree, 4: To a large degree and 5: To a very large degree (horizontal numbers in the $x$-axis in all the figures in the paper). Figure 2 presents the results of the participants' level of overall knowledge of autism /ASD in their work in 2014.

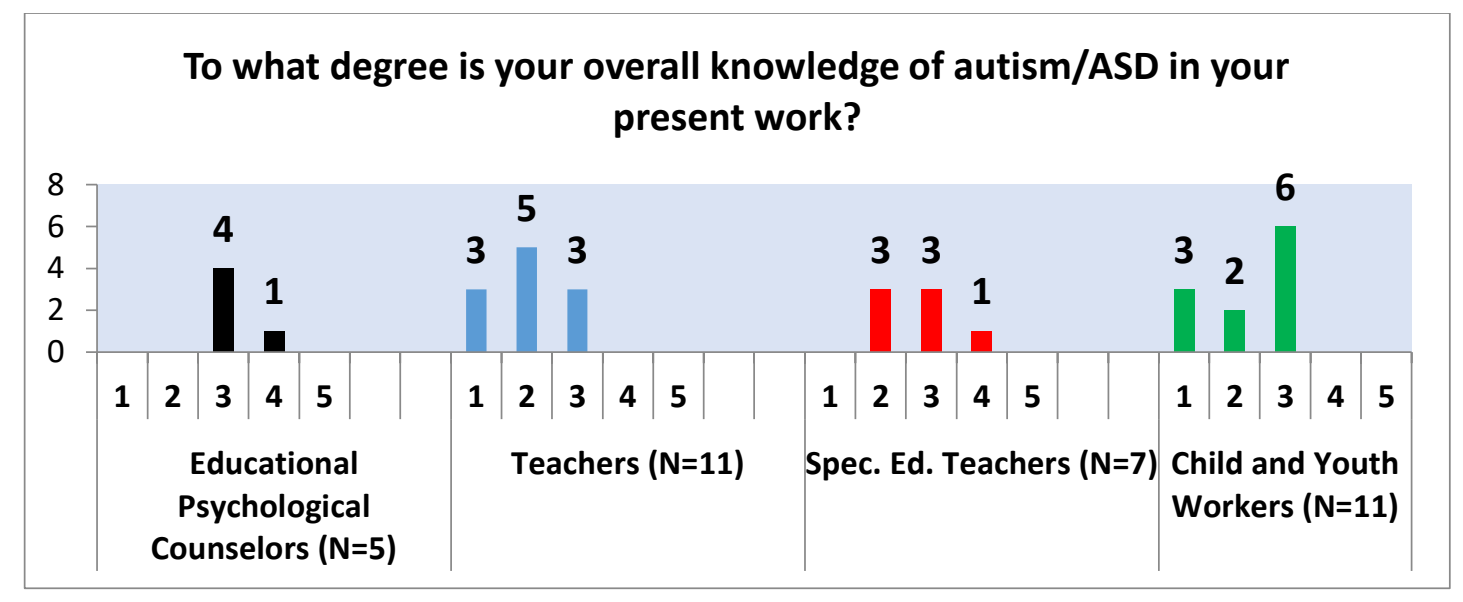

Figure 2. The participants' overall knowledge of autism/ASD in their present work

It is quite clear that all four groups of professionals who worked with children with autism/ASD had some degree of knowledge, but apart from one educational psychological counselor (EPC) and one special ed. teacher, none of the participants judged their overall knowledge to be at a large or a very large degree. One can say that this alone was a good enough reason for initiating the CIP.

Another factor that was considered to be important when investigating the relation and communication between educational psychological counselors on one side and the teachers, special ed. teachers, and CYWs on the other side, was the level of competence among the latter-mentioned three professional groups to understand the assessment report about the children with autism/ASD. The assessment reports usually include the results of the assessments conducted by different instances (i.e. medical specialists in neurodevelopmental disorders, language pathologists, special education experts in autism/ASD (from STATPED), and EPC's own assessments), which can be challenging to sift through. Understanding the content of these reports, however, is important for effective selection and implementation of methods, strategies, and tactics for creating adapted training and teaching environments for children with autism/ASD (Cooper, Heron \& Heward, 2007).

The following figure (3) shows the competence situation of the members of the three professional groups. 


\section{To what degree are you able to understand the assessment reports about children with autism/ASD from Educational Psychological Services?}

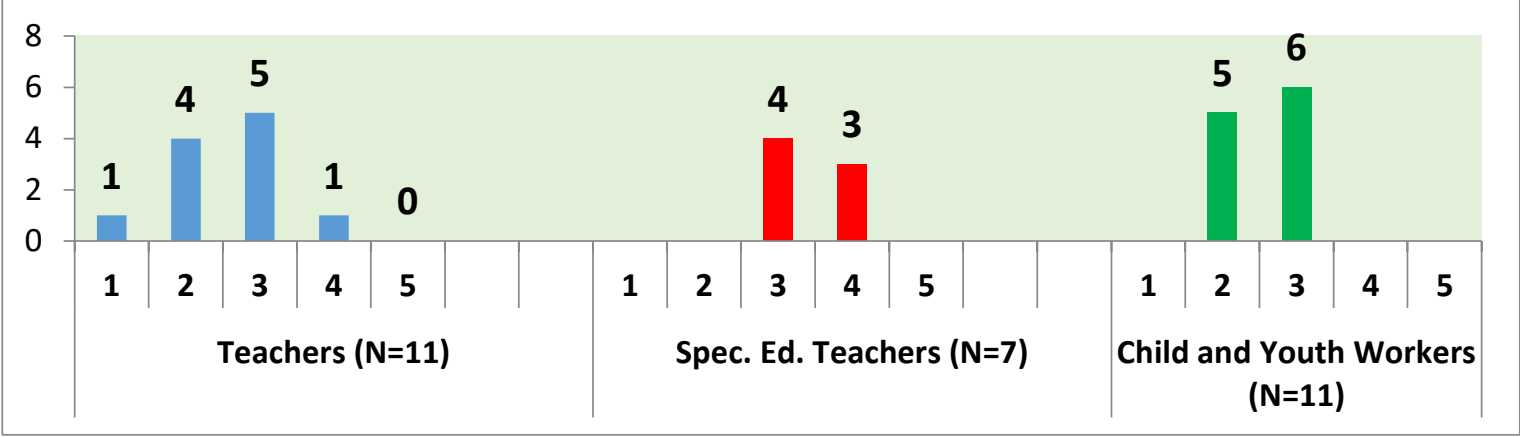

Figure 3. The participants' competence in understanding the assessment reports about children with autism/ASD from EPS

The results here show that only four of 18 practicing teachers and special ed. teachers (and none of the CYWs) could understand the assessment reports from the educational psychological services to a large degree at the time the CIP-municipality initiated the CIP. A vast majority of the teachers and special ed. teachers and all of the CYWs could only understand those assessment reports to some degree or less. This too is an excellent reason for initiating the CIP.

The results suggest that in 2014, at the beginning of the CIP, the children with autism/ASD met EPCs, teachers, special ed. teachers, and CYWs who were not confident enough with the knowledge they possessed. In other words, they did not have the necessary knowledge and competences to accomplish their jobs within the field of training and teaching of children with autism/ASD at a satisfactory level.

Another important factor in the training and teaching of children with autism/ASD is the relationship between those who are involved in the assessment, training, and teaching of children with autism/ASD and the parents of the children affected. Those who work within the field of autism/ASD know very well that parents are important stake holders. Good relationships, clear communication, and open collaboration with parents are important for effective learning and development of children with autism. The children spend a lot of time with their parents. Coordination of the work being done at the school with the children's life at home and outside the school is important for every child on the spectrum. This necessitates strong communication and coordination between the professionals and the parents.

The skills and knowledge developed in one-to-one-settings or group-settings at the school, however, often must be generalized. Generalization is recognized as one of the biggest challenges within the field of autism/ASD (Kasari, Dean, Kretzmann, Shih, Orlich, Whitney, Landa, Lord \& King, 2015; Koegel, Kuriakose, Singh \& Koegel, 2012; Özerk \& Özerk, 2013). The children must be provided the conditions and opportunities to transfer their skills and knowledge to real life situations.

With this in mind, in our pre-test, we asked the participants in all four groups to what degree each of them felt confident when they met parents of children with autism/ASD.

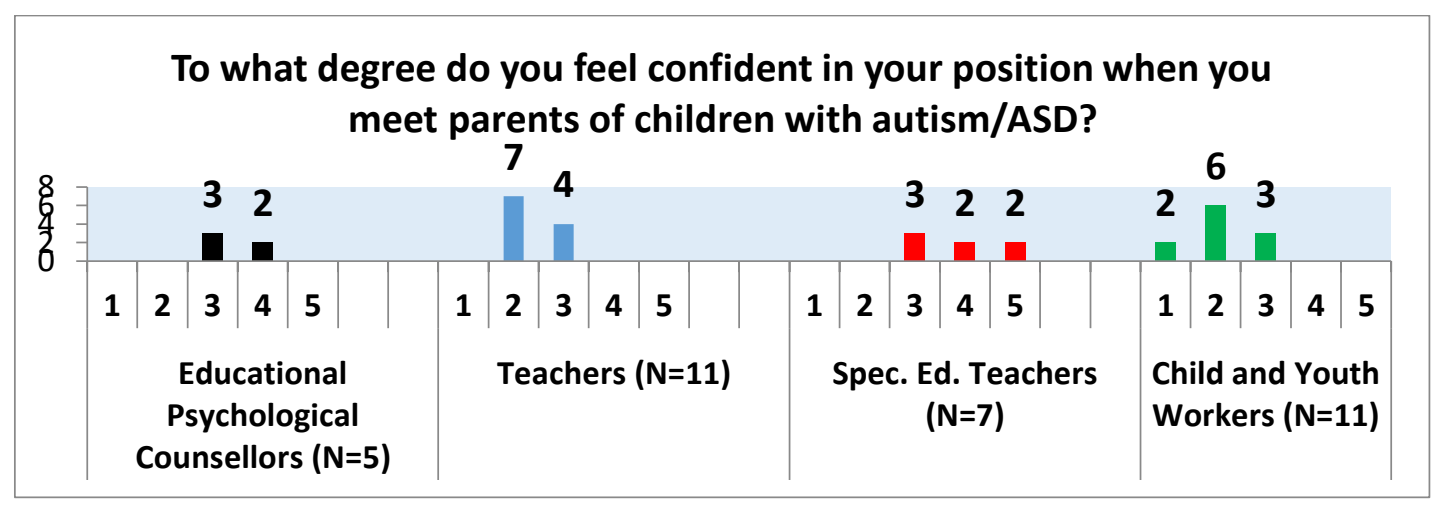

Figure 4. The three professional groups' feeling of confidence in meeting with the parents of children with autism/ASD.

As Figure 4 shows, the majority of the EPCs, teachers, and CYWs felt to some degree a lack of confidence when they met with parents. None of the members of the teachers- group and CYW-group felt confidence to a large or very large degree. The only professional group in which the majority of the group members felt confidence to a large 
or very large degree was the special ed. teachers. But even in this group 3 of 7 special ed. teachers felt confidence only to some degree.

If we are to summarize the findings so far, we can say that despite some positive elements in the CIP-municipality's professional groups' competence level, experiences, and feelings of confidence, the four participant groups of professionals needed competence improvement. In other words, the CIP-municipality had several good reasons for asking for and prioritizing the CIP. The EPCs, the teachers, the specialed. teachers, and the CYWs were in need of competence improvement in the challenging field of autism/ASD in a municipality where the incidence rate of autism during the project period was higher than the national and county averages. In the remaining sections of this paper, we will be presenting and discussing the results of post-tests following the CIP compared to the pre-test results at the beginning of the CIP.

\section{Three Methods and Their Theoretical Foundations}

As mentioned earlier, Discrete Trial Teaching (DTT), Pivotal Response Training (PRT), and Social Stories ${ }^{\mathrm{TM}}$ (SS) were three of the main topics in the CIP syllabus. The theoretical foundations of DTT, PRT, and SS were also presented with the help of the following figure:

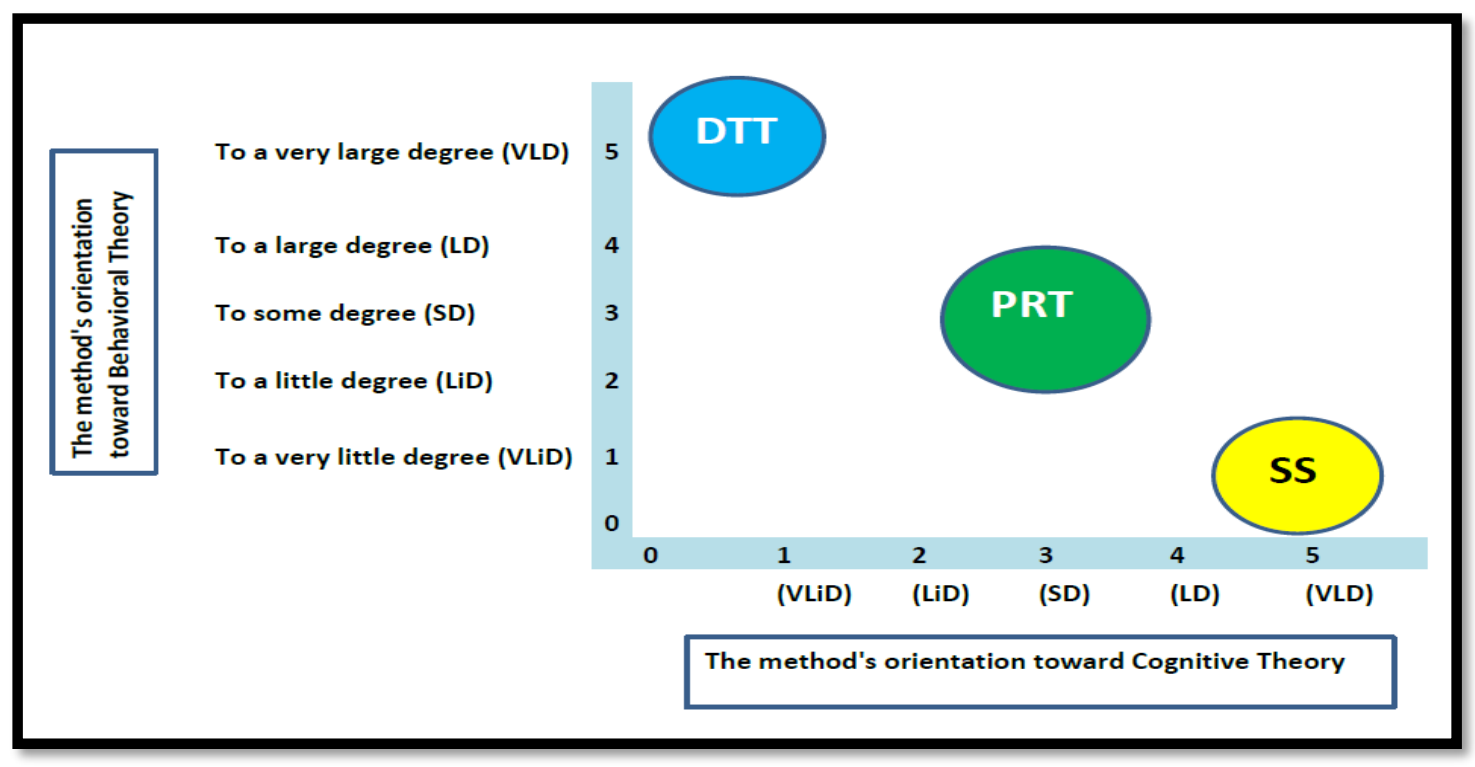

Figure 5. The three methods and their theoretical orientation

Based on the mentioned theoretical orientations of these methods, we used the following criteria for the correct answers:

--For DTT's behavioral theory relation: 4 and 5; to a large and to a very large degree respectively.

--For DTT's cognitive theory relation: 1 and 2; to a very little and to a little degree respectively.

--For PRT's behavioral theory relation: 3; to some degree.

--For PRT's cognitive theory relation: 3; to some degree.

--For SS's behavioral relation: 1 and 2; to a very little and to a little degree respectively

--For SS's cognitive theory relation: 4 and 5; to a large and to a very large degree respectively.

These three methods have been among the most recognized evidence-based and widely implemented methods within the field of autism/ASD (Gray, 2012; NAC, 2009). In addition to their theoretical orientations, the implementation of these three methods in practice was discussed through "case-presentations" and short video films.
In the following sections we'll present:

a) The results which show each of the four participant groups' knowledge about DTT, PRT, and SS at the end of the CIP (post-test) compared to in the beginning of the CIP (pre-test).

b) The results that show each of the four participant groups' conceptions about the theoretical orientations of DTT, PRT, and SS at the end of the CIP (post-test) compared to the beginning of CIP (pre-test).

Educational Psychological Counselors' Knowledge About DTT and Their Conceptions About DTT in Relation to Behavioral Theory and Cognitive Theory

Table 3 below shows the educational psychological counselors' (EPCs') knowledge about DTT that they could use in practice, the EPCs' conception of the DTT with regard to the method's relation to behavioral theory, and the EPCS' understanding of cognitive theory at the end of the CIP compared to at the beginning of the CIP. 
Table 3. Educational Psychological Counselors'self-evaluation of their knowledge and conceptions about DTT, PRT, and SS

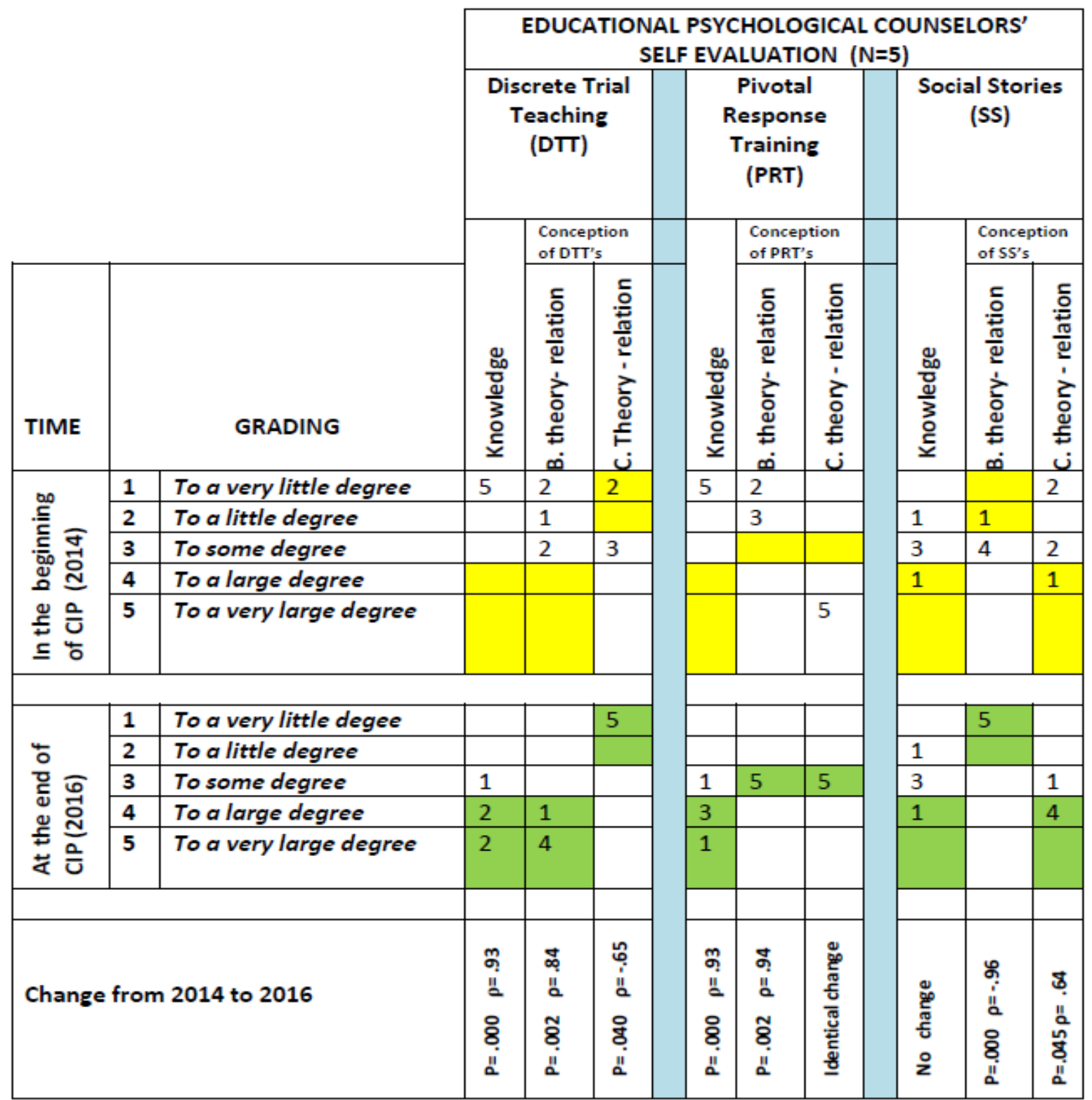

-The alternative answers to the questions were organized in ordinal scale in column 2 :

1: To a very little degree, 2: To a little degree, 3: To some degree, 4: To a large degree, and

5: To a very large degree. The numbers in front of these grades show the distribution of the answers given by the participants.

-The yellow colored boxes show the zones for correct answers at the beginning of the CIP (pre-test)

-The green colored boxed show the zones for correct answers at the end of the CIP (post-test)

-B-theory: Behavioral theory

-C-theory: Cognitive theory

The results in Table 3 show that EPCs, according to their self-evaluation, did not have enough knowledge about DTT and PRT to use these methods in practice at the beginning of the CIP. All of the EPCs signaled that they had a very little knowledge about DTT in the beginning of the CIP. At the end of the CIP, four of five had satisfactory knowledge (two at a large degree and two at a very large degree) and one of them gained knowledge about DTT to some degree. This improvement is significant $(P<.05, P=.000$ Spearman $\rho=.93)$ indicating that they improved their knowledge about DTT and PRT enough to make them capable of using these methods in practice (the year of pre-test (2014) coded as 1 and the year of post-test (2016) coded as 2 in SPSS).

When it comes to the question regarding the EPCs' conception about the relation between DTT and behavioral theory, it can be seen that all the EPCs had a misconception about DTT in the beginning of CIP, in 2014. As shown in Figure 4, DTT is a strong/very strong behavioral theory oriented method. The above results also show that there is a significant change in EPCS' preconception of DTT $(P<.05$, $p=.002$ and Spearman $p=.84$.) All of the EPCs considered DTT at the end of the CIP, in 2016, as a strong or very strong behavioral theory oriented method, which is correct. 
The other results related to DTT in the table reveal the EPCs' conceptions of the relation between DTT and the cognitive theory. Only two of five EPCs had a correct understanding of this relationship at the beginning of the CIP. At the end of the CIP, however, all the EPCs had the correct understanding of the DTT's little or very little cognitive orientation. Here also there is a significant improvement $(p<.05, p=.040$ and Spearman $p=-.65)$ in the EPCS' conception about the theoretical orientation of DTT. One can also see a very similar tendency in the development of the EPCS' knowledge about PRT and their conception about this method's theoretical orientation. Four of five EPCs improved their knowledge about PRT to a large or very large degree, and all of them improved their conception about PRT's theoretical relation to behavioral theory and cognitive theory. But with regard to SS, there was not any change. An important outcome in the CIP is that four of five EPCs improved their practice applicable knowledge and conceptions about DTT and PRT. They could thereafter accomplish their counselling jobs as competent counsellors when the challenge is related to DTT and PRT, but not if it is about SS. What about the other three professional groups' improvement?

The Teacher's Knowledge About DTT and Their Conception About DTT in Relation to Behavioral Theory and Cognitive Theory

As shown earlier, there were 11 teachers who completed the CIP and received certificates of attendance and who were therefore included in our paper. They answered the same questions as the EPCs. Table 4 below shows the results.

Table 4. The teachers'self-evaluation of their knowledge and conceptions about DTT, PRT, and SS

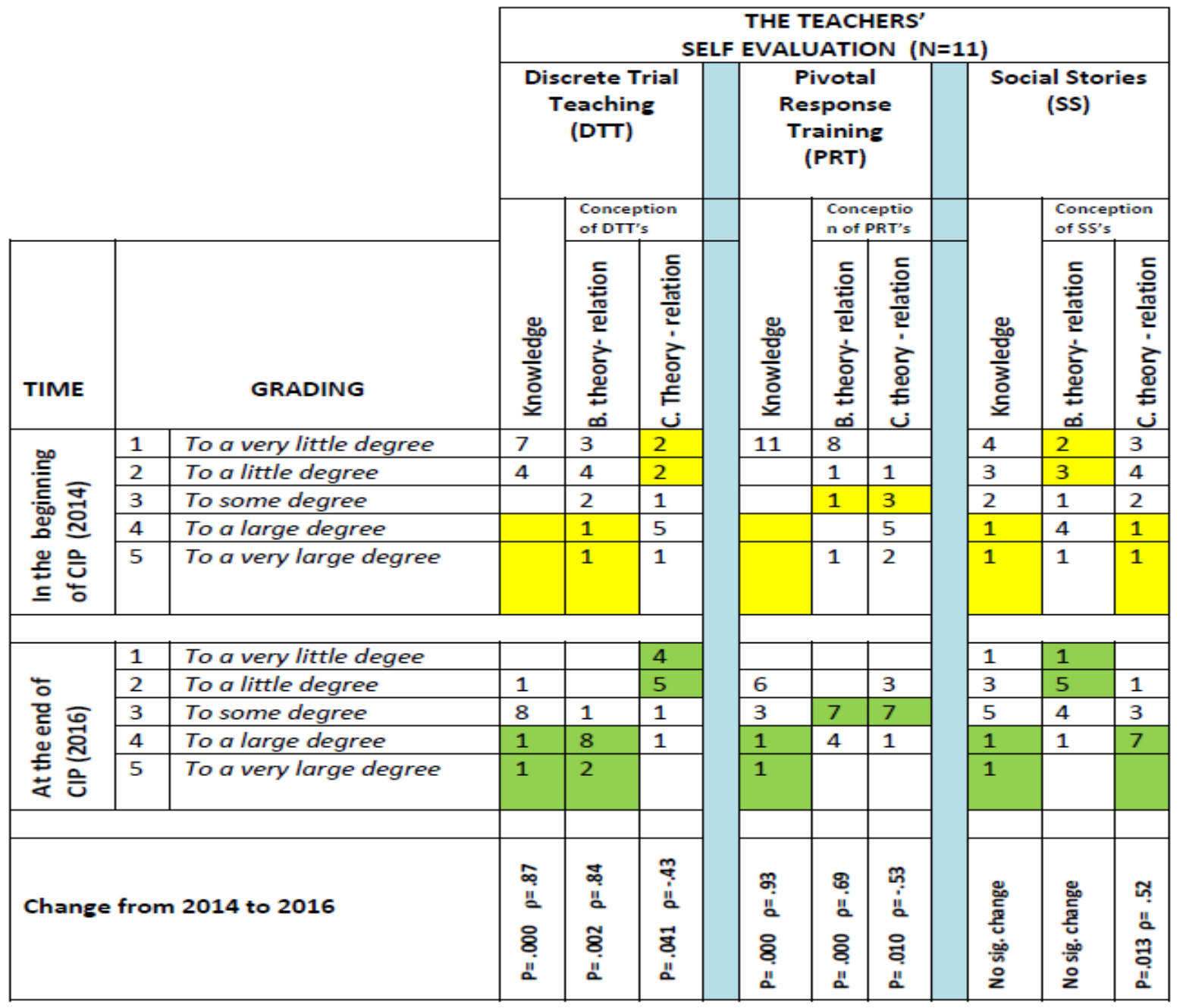

As the results in Table 4 show, only two of the teachers $(\mathrm{N}=11)$ had satisfactory knowledge about DTT to be able to use it in practice at the beginning of the CIP. As a group, their knowledge about DTT improved significantly $(p<.05)$ after the CIP $(p=.000$, and Spearman $p=.87)$ but in our judgment this improvement is not satisfactory for the teachers group. At the end of the CIP, only two of them felt that they had learned to a large degree or very large degree enough knowledge about DTT to be able to use this method in the training and teaching of children with autism/ASD. On the other hand, the teachers improved significantly in their conception about the relation between DTT and behavioral theory $(p<.0, p=.002$ and Spearman $p=$ .84) and experienced a significant change in their 
conception about the relation between DTT and cognitive theory ( $p=.041$ and Spearman $p=-.43$.) The results in the above table also show that the teachers as a group have significantly improved knowledge about PRT ( $p=.000$ and Spearman $\rho=.93$ ), but only two of the eleven teachers judged their own knowledge to be at a large degree or very large degree. This means that significant improvement does not equate in this case to a satisfactory level of improvement. The teachers' partial misconception of PRT's relationship with behavioral theory at the beginning of the CIP was corrected significantly $(p=.000$ and Spearman $p=$ .69) from pre-test to post-test, from the beginning of the CIP to the end of the CIP. The same is also valid for their conception about PRT's relation to cognitive theory $(P=.010$ and Spearman $\rho=-.53$ ).

With regard to the teachers' knowledge about SS, their knowledge of SS did not change significantly. Only two of eleven teachers had satisfactory knowledge about this method in the beginning and at the end of the CIP. Additionally, five of eleven of them had correct conceptions about SS's relation to behavioral theory at the beginning of the CIP, with that number improving to six by the end of the CIP. The change is not significant.

When it comes to SS's relation to cognitive theory, however, a significant change has occurred $(P=.013$ and Spearman $\rho=.52$ ). Seven of eleven teachers at the end of the CIP, compared to two at the beginning of the CIP, had correct conceptions. The teachers' overall results show that though there were some improvements in their conception of the three methods at the conclusion of the CIP, a vast majority still did not feel that they learned satisfactory enough knowledge about the three methods to allow them to use them for training and teaching children with autism. What is the situation for special ed. teachers?

The Special ed. Teachers' Knowledge About DTT and Their Conception About DTT in Relation to Behavioral Theory and Cognitive Theory

There were seven special ed. teachers in the sample. Table 5 shows their knowledge about DTT and their conception about DTT in relation to behavioral theory and cognitive theory.

Table 5. The special education teachers' self-evaluation of their knowledge and conceptions about DTT, PRT, and SS.

\begin{tabular}{|c|c|c|c|c|c|c|c|c|c|c|c|}
\hline & & & & & HES & $\begin{array}{l}\text { ALE } \\
\text { EVA }\end{array}$ & $\begin{array}{l}\text { UCAT } \\
\text { UATIC }\end{array}$ & $\begin{array}{l}\text { ON } \\
N(1\end{array}$ & $\begin{array}{l}\text { CHEF } \\
\text { L) }\end{array}$ & & \\
\hline & & & & $\begin{array}{l}\text { erete } \\
\text { each } \\
\text { (DT }\end{array}$ & & & $\begin{array}{l}\text { Pivota } \\
\text { espon } \\
\text { rainin } \\
\text { (PRT) }\end{array}$ & & & $\begin{array}{l}\text { I Stc } \\
\text { (SS) }\end{array}$ & \\
\hline & & & & $\begin{array}{l}\text { Con } \\
\text { of } D \\
\end{array}$ & $\begin{array}{l}\text { tion } \\
\end{array}$ & & $\begin{array}{l}\text { Conc } \\
n \text { of }\end{array}$ & $\begin{array}{l}\text { etio } \\
\text { 'RT's }\end{array}$ & & $\begin{array}{l}\text { Conc } \\
\text { of } \mathrm{S}\end{array}$ & tion \\
\hline TIME & & GRADING & 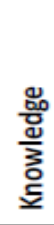 & 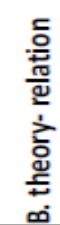 & 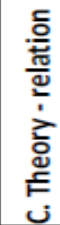 & 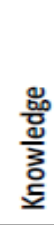 & 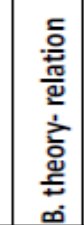 & 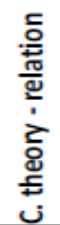 & 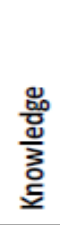 & 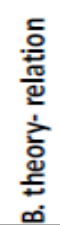 & 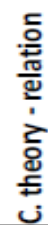 \\
\hline & 1 & To a very little degree & 5 & 3 & 2 & 6 & 2 & & 3 & & \\
\hline 喜- & 2 & To a little degree & 2 & 1 & 1 & 1 & 3 & & & 4 & 4 \\
\hline 言 & 3 & To some degree & & 1 & 2 & & 2 & 2 & 3 & 2 & 1 \\
\hline ఖั 이 & 4 & To a large degree & & 2 & 2 & & & 5 & 1 & 1 & 2 \\
\hline $\begin{array}{l}\text { 은 은 } \\
\text { 든 }\end{array}$ & 5 & To a very large degree & & & & & & & & & \\
\hline & & & & & & & & & & & \\
\hline & 1 & To a very little degee & & & 6 & & & & & & \\
\hline & 2 & To a little degree & & & 1 & & & 1 & & 5 & \\
\hline 흔 & 3 & To some degree & 1 & & & 1 & 7 & 6 & 1 & 2 & \\
\hline 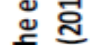 & 4 & To a large degree & 4 & 3 & & 4 & & & 4 & & 5 \\
\hline 走 & 5 & To a very large degree & 2 & 4 & & 2 & & & 2 & & 2 \\
\hline & & & & & & & & & & & \\
\hline Chang & 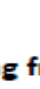 & m 2014 to 2016 & $\begin{array}{l}\text { के } \\
\text { घ! }\end{array}$ & $\begin{array}{l}\stackrel{2}{a} \\
a \\
a\end{array}$ & $\begin{array}{l}n \\
\ddot{i} \\
\text { in }\end{array}$ & $\begin{array}{l}\text { ने } \\
\text { ä }\end{array}$ & $\begin{array}{l}\tilde{N} \\
\mathrm{a} \\
\mathrm{a}\end{array}$ & $\begin{array}{l}\text { R } \\
\text { i } \\
\text { i }\end{array}$ & $\begin{array}{l}\text { p } \\
\text { ia }\end{array}$ & 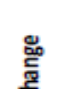 & $\begin{array}{l}\text { D } \\
\text { ii }\end{array}$ \\
\hline & & & $\begin{array}{l}\text { षे } \\
\text { ii }\end{array}$ & ï & $\begin{array}{l}\text { ọ } \\
\text { ii } \\
\text { a }\end{array}$ & $\begin{array}{l}\text { 8े } \\
\text { II }\end{array}$ & 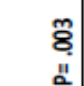 & ఫิ & 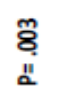 & $\begin{array}{l}\frac{5}{0} \\
\frac{0}{5} \\
0 \\
0\end{array}$ & ఫิ \\
\hline
\end{tabular}

The results show that special ed. teachers as a group significantly improved their knowledge about DTT - enough so that they could use the method in their practices ( $\mathrm{p}=.000$ and Spearman $\rho=.90)$. Furthermore, they improved their conception of the relationship between DTT and behavioral theory $(p=.001$ and Spearman $p=.79)$ and between DTT and cognitive theory $(p=.016$ and Spearman $\rho=-.63)$. An important improvement seems to 
be in their knowledge about DTT that make them able to use the method in practice. At the beginning of the CIP, all of the special ed. teachers had very little or a little degree of knowledge about DTT related to the training and teaching of children with autism/ASD. At the end of the CIP, 6 of 7 learned to a large or very large degree knowledge about DTT that they could then use in practice. A similar significant and satisfactory improvement is seen with regard to the special ed. teachers' development of their knowledge about PRT ( $p=.000$ and Spearman $p=.91)$ and to their conception about the relation between PRT and behavioral theory $(p=.003$ and Spearman $p=.72)$ and their conception about PRT and the method's relation to cognitive theory $(p=.002$ and Spearman $\rho=-.74)$.

A similar tendency can also be seen in their improvement with regard to their knowledge about SS ( $p=.003$ and Spearman $\rho=.73$ ) and their conception about the relationship between SS and the cognitive theory $(p=.002$ and Spearman $\rho=.74$ ). Of note, there was no significant change in their conception about the relation between SS and behavioral theory. But, as can be seen in the table, this happened because four of seven special ed. teachers had correct conceptions of this relationship at the beginning of the CIP, and five of seven special ed. teachers had the same correct conception at the end of the CIP. In other words, no significant change does not, at least in this case, equate to a negative trend. In all, the results by the special ed. teachers suggest that they as a group benefited from the CIP at a very satisfactory level. In the next section we'll present and discuss the results obtained by child and youth workers (CYWs).

Child and Youth Workers' Knowledge About DTT and Their Conception About DTT in Relation to Behavioral Theory and Cognitive Theory

There were 11 child and youth workers (CYWs) who completed the CIP. Table 6 below shows the results.

Table 6. The Child and Youth Workers' Self-Evaluation of Their Knowledge And Conceptions About DTT, PRT, And SS

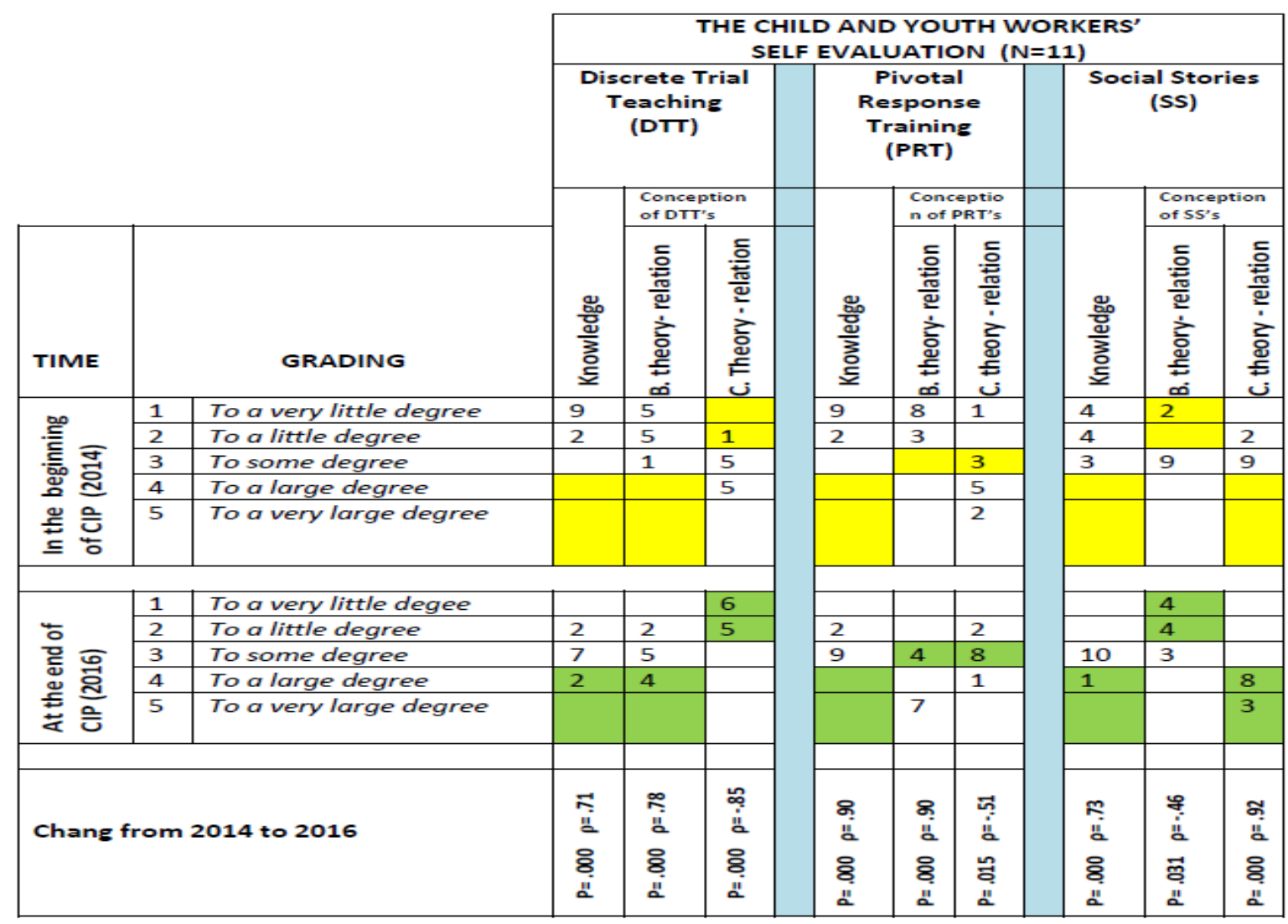

CYWs as a group made significant improvement of their knowledge about DTT ( $p=.000$ and Spearman $p=.71)$ and in their conception about the relation between DTT and behavioral theory $(p=.000$ and Spearman $\rho=.78)$ and between DTT and cognitive theory $(p=.000$ and Spearman $\rho=-.85)$. The significant improvement in the groups' knowledge of DTT, however, is not satisfactory. That said, two of them did become knowledgeable to the degree that they could use the method in training and teaching children with autism/ASD. A similar tendency can also be seen in CYWs' knowledge about PRT and SS. Improvement during the CIP with regard to their knowledge about SS is significant but, again, not satisfactory. None of them felt that they learned knowledge about PRT that they could use in practice, and only one of them felt that his/her knowledge about SS was satisfactory enough to be used in training and teaching children with autism/ASD.

The results so far show that the CIP contributed to varying degrees of knowledge improvement among the participant groups, regarding the three methods that they could use in practice, and about their conceptions of the methods' 
theoretical orientation. With this picture as a background, we'll now return to the following questions and compare and discuss the findings:

-To what degree did the members of the four professional groups have overall knowledge about autism/ASD in their work at the end of the CIP compared to at the beginning of the CIP?

-To what degree were the members of the three professional groups able to understand the assessment reports from educational psychological services about children with
autism/ASD at the end of the CIP compared to at the beginning of the CIP?

-To what degree did the members of the four professional groups feel confident in their position when they met parents of children with autism/ASD at the end of the CIP compared to at the beginning of the CIP?

The Four Professional Groups' Degree of Overall Knowledge About Autism/ASD in Their Present Work at The End of The CIP Compared to at The Beginning of The CIP

Table 7. The participant's Self-Evaluation Of Their Overall Knowledge About Autism/ASD in Their Present Work

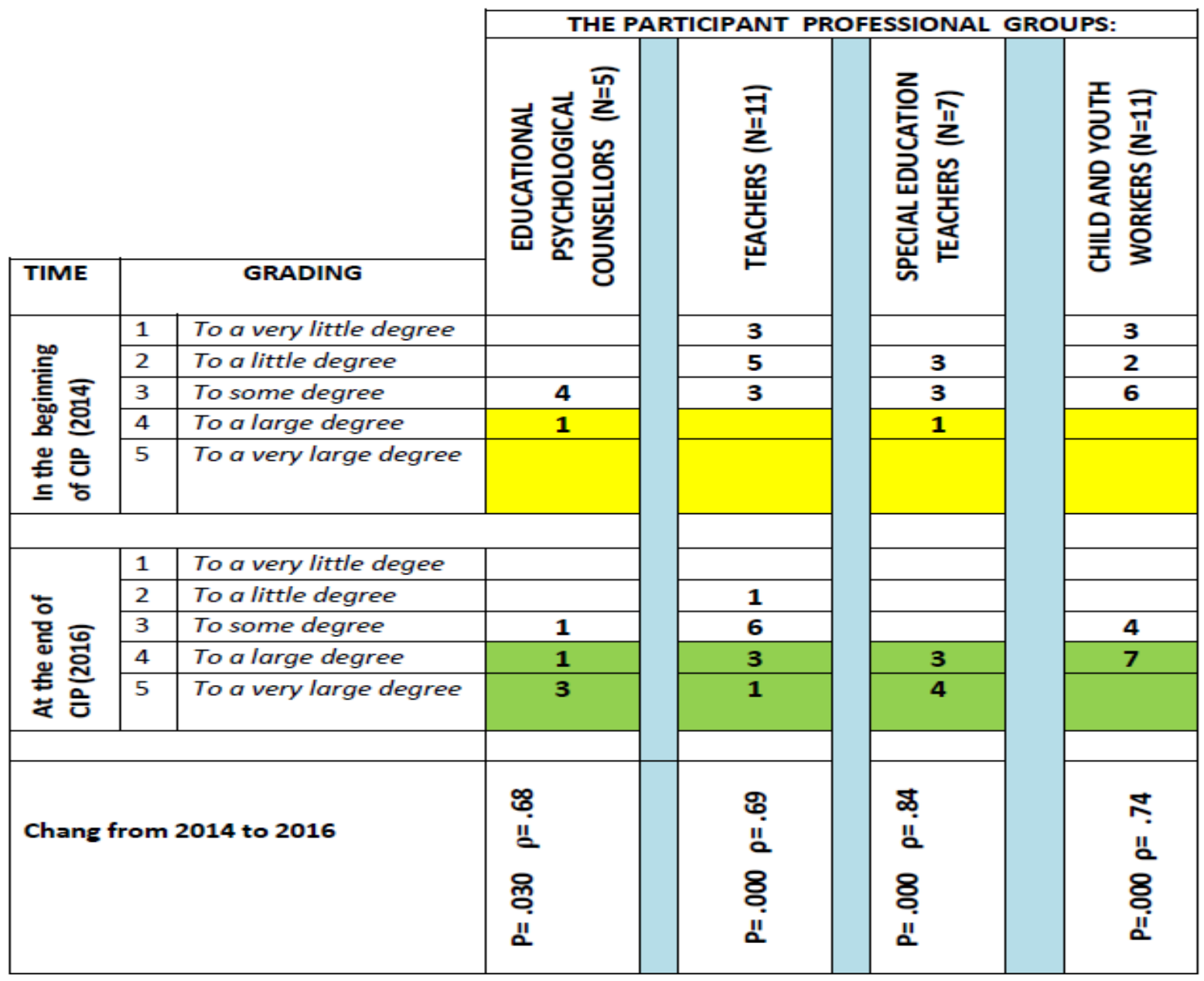

The pre-test parts of these results were also presented separately in the beginning of our paper (see Figure 2), where we concluded that a low degree of confidence among the four professional groups was a 'good' reason on its own for initiating the CIP. As one can see from the participants' answers in Table 7, the CIP contributed significantly to the improvement of all the participant groups' overall knowledge about autism/ASD. A vast majority of the EPCS and CYWs and all special ed. teachers considered their overall knowledge about autism/AS to have been improved at a large or a very large degree. We consider this significant and satisfactory improvement in the overall knowledge of four of five EPCs, all the special ed. teachers, and of the vast majority of CYWs as an important pedagogical asset to be kept updated and utilized in the CIP-municipality.

On the other hand, only four of eleven teachers considered their overall knowledge of autism/ASD to be at satisfactory level at the close of the CIP. These four teachers are also a part of the CIP municipality's accumulated pedagogical assets.

These results also reveal that the four educational psychological counsellors with satisfactory overall knowledge about autism/ASD are within a larger group of 22 practicing professionals possessing satisfactory overall 
knowledge about autism/ASD. Together, within the CIPmunicipality, they can communicate and discuss issues to solve the challenges encountered in their training and teaching of children with autism/ASD.

An important aspect of communication between educational psychological counsellors and the practicing teachers, special ed. teachers, and CYWs relies on reading and understanding the assessment reports and communicating pedagogical issues from common reference points. With this in mind, we considered the following question as important: -To what degree were the members of the three professional groups able to understand the assessment reports from educational psychological services about children with autism/ASD at the end of CIP compared to in the beginning of CIP? Table 8 presents the self-evaluation results of the three participant groups' competency to understand the assessment reports from the educational psychological services (from EPCs) at the end of the CIP compared to their evaluation at the beginning of the CIP.

Table 8. The Participants' Self-Evaluation of The Degree of Their Understanding of The Assessment Reports From The Educational Psychological Services (EPS)

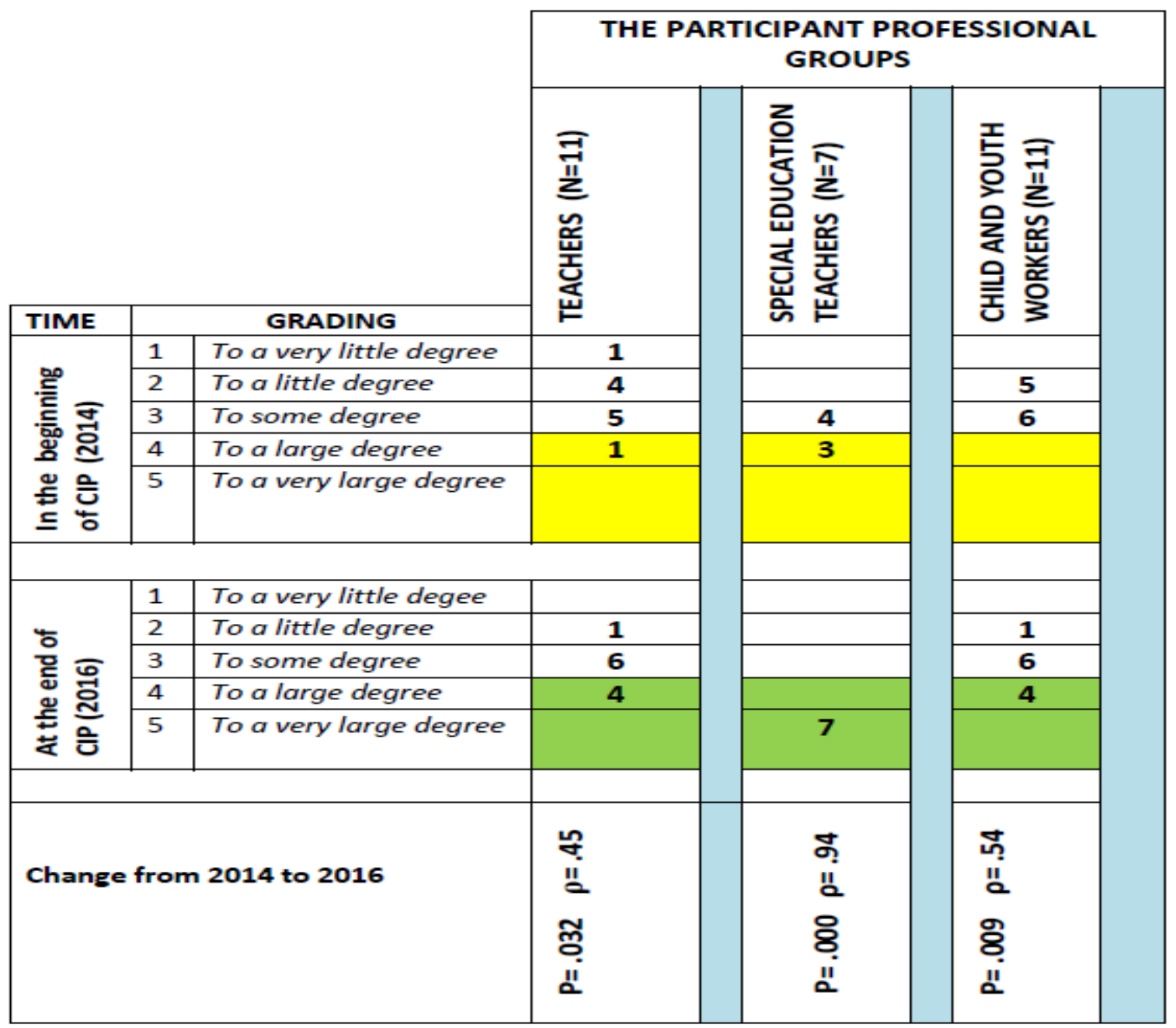

The table makes clear that there has been significant improvement in the competency level of the participants. While one of the teachers and none of the CYWs had competence to understand assessment reports at the beginning of the CIP (see also Figure 3), there were four teachers and four CYWs who felt capable of doing that at the end of the CIP. Despite this significant improvement in these two groups, though, less than half of the groups considered themselves capable of understanding the assessment reports about children with autism/ASD at the end of the CIP. Still, the special ed. teachers all considered themselves capable of understanding the assessment reports about children with autism/ASD to a very large degree at the end of the CIP compared to just three of them in that position at the beginning of the CIP.

As we discussed earlier, close and good relationships, communication, and collaboration with parents are important for the creation of good learning conditions for children with autism/ASD. To achieve successful learning skills for social interaction, social communication, and adaptive skills, close and effective coordination between what is being done at the school and what is being done at home or home environment is essential. Transferring and generalization of the skills and knowledge they learn and 
develop at organized and structured settings to real life settings is of the utmost important for this group -but at the same time, it is a huge challenge. We asked the participants to what degree they felt confident when they met the parents of children with autism/ASD that they worked with.

Table 9. The Four Professional Groups' Feeling of Confidence in Their Position When They Meet Parents of Children With Autism/ASD at The End of The CIP as Compared to at The Beginning of The CIP

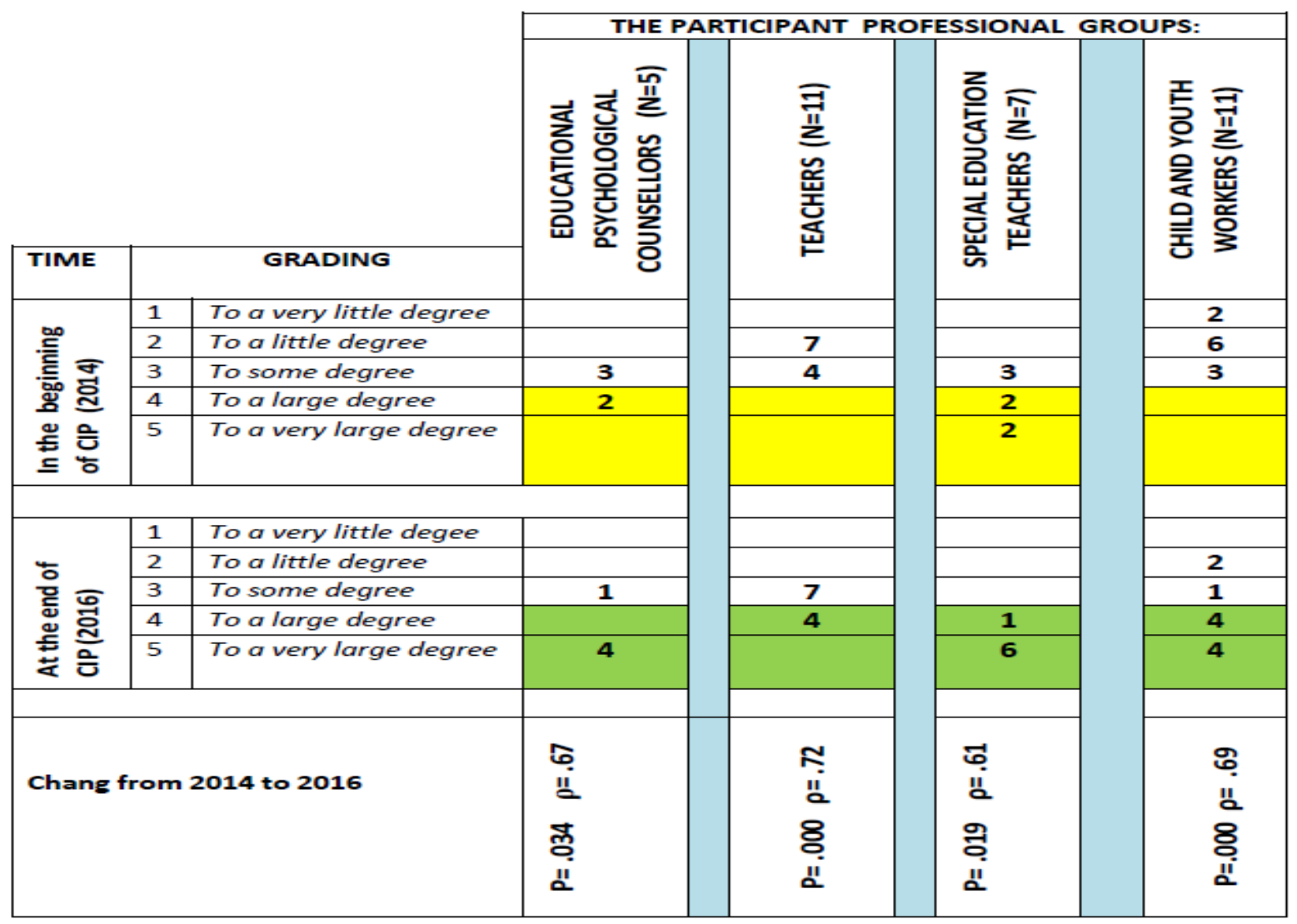

In the beginning of the CIP, there were only six participants (two EPCs and four special ed. teachers) who felt a high degree of confidence when meeting the parents of children with autism/ASD. At the end of the CIP, 23 of the participants (4/5 EPCs, 4/11teachers, all seven special ed. teachers, and $8 / 11 \mathrm{CYWs}$ ) had a large to very large degree of confidence in their position when meeting the parents of those children with autism/ASD that they work with. Except in the teachers' group, the majority of the members of all the other professional groups improved their level of confidence as professionals when meeting their most important collaboration partner, the students' parents. Another positive point here is that while only two of five EPCs felt a large degree of confidence in their position in 2014 when meeting with parents, at the end of the CIP four of five of them felt confident to a very large degree. We consider the overall improvement in this area as an important and significant outcome of the CIP and a positive factor for collaboration with the parents in the CIPmunicipality in the post-CIP period.

\section{Discussion}

The results presented above reveal a very clear tendency. The EPCs and special ed. teachers as groups improved their knowledge about DTT and PRT as well as their conceptions about these two methods' relations to behavioral theory and cognitive theory. Thus, we can say that a vast majority in both groups improved their knowledge that can now be used in training and teaching children with autism/ASD. We can also interpret the results of these two professional groups as indicating they have now developed common concepts about and a better understanding of DTT and PRT. They have, through the CIP, established a common repertoire of knowledge and theoretical understanding that could make it easier for the EPCS to succeed in their work and for their professional collaborations with special ed. teachers to improve, enhancing the quality of the training and teaching they provide for children with autism/ASD.

When it comes to the other two professional groups, the results reveal that this type of CIP was not enough for the teachers as a group or the CYWs as a group to improve their knowledge satisfactorily enough to practice DTT and PRT in training and teaching children with autism/ASD. This is our conclusion for these two groups despite the fact that there has been significant improvement in their conception about these two methods' theoretical bases. The CIP has provided opportunities for the teachers and the CYWs to gain significant improvement but not quite satisfactory improvement in their applicable knowledge. 
The third method that the CIP targeted to improve the participant professional groups' competence and conception was Social Stories $^{\mathrm{TM}}$ (SS). The results of the CIP with regard to this method are mixed. A vast majority of the EPCs, the teachers, and CYWs did not feel at the end of the CIP that they had learned enough knowledge about SS to use it in practice, even though all of the EPCS and the vast majority of teachers and CYWs improved their conception about the method's theoretical foundation. The only professional group of practitioners that gained significant and satisfactory improvement as a group in SS was special ed. teachers. A serious consequence of this situation is that special ed. teachers will not have access to competent educational psychological counselling related to SS's implementation in practice.

Other notable conclusions that one can draw from the above results include the following:

a) The CIP-municipality have four (out of five) competent EPCs in DTT and PRT as a result of the CIP

b) None of the professional groups have access to competent EPCS in SS in the CIP-municipality

c) In the wake of the CIP, the CIP-municipality has teachers and CYWs that improved their conceptions about the theoretical bases of DTT, PRT, and SS significantly.

d) The CIP did not succeed in making two of the professional groups (the teachers and CYWs) competent enough to successfully implement DTT, PRT, and SS in the training and teaching of children with autism/ASD. Nonetheless, the CIP contributed to the development of four competent EPCS who can help them in DTT and PRT if they establish conditions for good collaboration

e) The CIP led to a significant and satisfactory improvement in the overall knowledge of four of five EPCs, all the special ed. teachers, and the vast majority of CYWs. This is an important pedagogical asset to be kept updated and utilized in the CIPmunicipality. Even though only four of eleven teachers now consider their overall knowledge of autism/ASD to be at satisfactory level, they are also a part of the CIP municipality's accumulated pedagogical assets.

f) All of the special ed. teachers considered themselves capable enough to understand the assessment reports about children with autism/ASD to a very large degree at the end of the CIP. On the other hand, less than half of the teachers and CYWs improved their competence enough to understand the assessment reports about children with autism/ASD.

g) At the end of the CIP, 23 of the participants (four of five EPCs, four of 11 teachers, all seven special ed. teachers, and eight of 11 CYWs) had to a large or very large degree of confidence in their position when they meet with the parents of children with autism/ASD that they work with.
These results also suggest that significant improvement in overall knowledge and conception about the theoretical orientations of DTT, PRT, and SS does not necessarily equate to satisfactory improvement in practical applicable knowledge about the methods. Given that the results show that the EPCs and special ed. teachers are the two groups that most benefited from the CIP, one can assume that it is very likely that their relevant prior educational background accounts for their receptiveness to the CIP's curriculum. The teachers and CYWs do not have as strong a focus on the training and teaching of children with autism/ASD in their educational background as EPCs and special ed. teachers. This is also likely valid for their experience background. With this in mind, one can talk about the Matheus-effect in the process of competence improvement: The more relevant the educational and experience background that one has, the more benefits a person gets from CIP-type of competency improvements projects. When a vast majority of all participants improved their conception of the methods' theoretical orientation, but not all of them improved their practical applicable knowledge, this tells us that it is important to have a competence improvement project that not only enriches the professionals' theoretical repertoire, but also their operational competence.

Thus, our findings suggest that the type of CIP that we conducted must be supplemented by more practiceoriented and practice-near CIPs in the future. The training and teaching of children with autism/ASD needs theoretically strong practitioners, but also practicecompetent professionals: EPCs, teachers, special ed. teachers, and CYWs. Such a double competency is important for the improvement of the operational level in the field of autism/ASD.

The limitation of our study and thus of this CIP is that the theory-practice combination was not explicitly targeted due to the limited amount of hours that were in the CIP's disposition: sixteen, half-day, in-person classes during a two-year period. As a result of this schedule, the participants did not receive direct counselling and supervision in the practice field. This includes the training and teaching of children individually, in a group, in inclusive settings, in self-containing groups, or special units at the schools and the kindergartens. A future practiceoriented CIP should include initiatives and curricula that allow for a) more frequent classes, b) more time devoted to the recognized methods, c) more theory/practice combination, and d) more direct counselling and supervision in the field than the CIP we conducted. Such work may have the potential to strengthen our knowledge about how we can implement collective CIPS that can more effectively improve a) the EPCs' counseling competency and b) the other practitioners' practical competency for utilizing recognized methods for training and teaching children with autism/ASD.

\section{References}

Baron-Cohen, S., Scott, F. J., Allison, C., Williams, J., Bolton, P., Matthews, F. E. \& Brayne, C. (2009). Prevalence of autism-spectrum conditions: UK school-based 
population study. The British Journal of Psychiatry. 194, pp 500-509. DOI:10.1192/bjp.bp.108.059345.

Cardinal, D. \& Griffiths, A-J. (2016). Summary of findings. Report presented at the Inagural Disability Summit. Orange: Chapman University, Thompson Policy Institute.

Cooper, J. O., Heron, T. E. \& Heward, W. L. (2007). Applied behavior Analysis. Upper Saddle River, New Jersey: Pearson Merrill Prentice Hall.

Darling-Hammond, L. \& Sykes, G. (1999). Teaching as the learning profession. San Francisco, CA: Jossey-Bass Publishers.

Darling-Hammond, L., Wie, R., Andree, A., Richardson, N., \& Orphanos, S. (2009). Professional learning in the learning profession. Washington, DC: National Staff Development Council.

Fombonne, E., Quirke, S., \& Hagen, A. (2011). Epidemiology of pervasive developmental disorders. In D. G. Amaral, G. Dawson, \& D. H. Geschwind (Eds.), Autism spectrum disorders. New York: Oxford University Press.

Frea, W. D. \& Vittimberga, G. L. (2000). Behavioral interventions for children with autism. In J. Austin \& J.E. Carr (Eds.), Handbook of Applied Behavior Analysis. Reno, NV: Context Press.

Fullan, M. G. (1992). Successful School Improvement. Buckingham: Open University Press.

Gundersen, T. og Hem K-G (2005). Brukerundersøkelse blant personer med diagnose innen autismespekteret. Erfaringer med Autismenettverket- 09-15 STF78 A054504.

Kasari, C., Dean, M., Kretzmann, M., Shih, W., Orlich, F., Whitney, R., Landa, R., Lord, C. \& King, B. (2015). Children with autism spectrum disorder and social skills groups at school: A randomized trial comparing intervention approach and peer composition. Journal of Child Psychology and Psychiatry and Allied Disciplines. DOI: $10.1111 /$ jcpp. 12460

Koegel, L.K, Kuriakose. S., Singh, A.K \& Koegel, R. L (2012). Improving generalization of peer socialization gains in inclusive school settings using initiations training. Behavior Modification 36(3), 361-77. DOI: 10.1177/0145445512445609.

Koegel, R.L., Kim, S. \& Koegel, L.K. (2014). Training Paraprofessionals to Improve Socialization in Students with ASD. Journal of Autism and Developmental Disorders. Volume 44, Issue 9, pp 2197-2208. https://doi.org/10.1007/s10803-014-2094-x

Matson, J. L. \& Kozlowski, A. M., (2011). The increasing prevalence of autism spectrum disorders. Research in Autism Spectrum Disorders, 5, 418-424.

Ministry of Education and Research (2006): National Curriculum for Knowledge Promotion in Primary and Secondary Education and Training 2006.

The National Autism Center's (2009): The national standards project-Addressing the Need for Evidence-based Practice
Guidelines for Autism Spectrum Disorders, Randolph, MA: The National Autism Center.

National Autistic Society (2006). http://www.autism.org.uk/about/what-is.aspx.

Accessed 03.03.2016)

Özerk, M. and Özerk, K. (2013). Autisme og pedagogikk. (Autism and Pedagogy). Oslo: Cappelen Damm Akademisk.

Özerk, K. (2016): The Issue of Prevalence of Autism/ASD. International Electronic Journal of Elementary Education, 9 (2), 263-306.

Stoltenberg, C., Schjølberg, S., Bresnahan, M., Hornig, M., Hirtz, D., Dahl, C.,Lie, K.K. Reichborn-Kjennerud, T., Schreuder, P., Alsaker, E., Øyen, A-S., Magnus, P., Surén, P., Susser, E. \& Lipkin, W.I. \& The ABC Study Group (2010). The Autism Birth Cohort: a paradigm for geneenvironment-timing research. Molecular Psychiatry 15, 676-680.

Surén, P., Bakken, I.J., Aase, H, Chin, R., Gunnes. N., Lie, K.K., Magnus. P., Reichborn- Kjennerud, T., Schjølberg, S., Øyen, A-S. \& Stoltenberg, C. (2012). Autism spectrum disorder, ADHD, epilepsy, and cerebral palsy in Norwegian children. Pediatrics 130: 152 - 158.

Zablotsky, B., Black,L. I., Maenner, M.J., Schieve, L.A, Blumberg, S. J. (2015). Estimated Prevalence of Autism and Other Developmental Disabilities Following Questionnaire Changes in the 2014 National Health Interview Survey. National Health Statistics Reports nr 87, 13th of November, 2015. Hyattsville, MD: U.S. Department of Health and Human Services Centers for Disease Control and Prevention (CDC), National Center for Health Statistics (NCHS). 